\title{
THE ELECTROCARDIOGRAM OF ALCOHOLIC CARDIOMYOPATHY
}

\author{
BY \\ WILLIAM EVANS \\ From the Cardiac Department of the London Hospital
}

Received December 1, 1958

The harmful effects of excessive alcohol consumption on the liver have long been recognized. A corresponding injury to the heart has not received the same attention except as part of the syndrome of beriberi attributable to thiamine deficiency. Not infrequently, however, when some form of heart disease is suspected on account of symptoms like breathlessness, palpitation, or chest pain, and when signs elicited from examination of the heart are equivocal, the true diagnosis may go undiscovered, especially if coronary arterial disease is too readily imputed as the cause of electrocardiographic changes that may be present. In such instances, information about the quantity of alcohol consumed is seldom sought, and addiction to it is not rigorously canvassed.

It should be known that when the ill-effects of alcohol on the myocardium are slight, withdrawal of alcohol can halt the pathological process, but should these earlier injurious effects go unheeded through some years, the resulting cardiomyopathy will no longer subside following such abstinence. It is for this reason that early myocardial damage from alcoholism is so important to detect, and it is the purpose of this paper to describe changes in the electrocardiogram that will facilitate this readier recognition.

\section{How the Patients were Assembled}

The first patient in this series attended at the request of his family doctor on account of breathlessness and with a history of alcoholism over many years. His electrocardiogram presented a change that had not been noticed hitherto in healthy adults nor in patients with coronary arterial disease. The remaining 19 patients were assembled because of their bizarre symptoms and signs associated with characteristic electrocardiographic changes, and before a history of alcoholism was obtained. Indeed, in two cases where changes in the cardiogram by itself appeared to warrant the view that they had resulted from alcoholism, both patients denied habitual spirit drinking until inquiry of spouse and family doctor had confirmed such addiction through many years.

\section{The EleCtrocardiogram}

In 17 of the 20 patients the tracing showed changes that were confined to the $T$ wave and followed characteristic designs. In the remaining three, the injurious effects of alcohol on the heart were suspected from finding extrasystoles of a certain order alongside other clinical signs that themselves supported the diagnosis. Thus, the cardiographic deformities have been allocated to two groups for the purpose of description, namely those that seemed by themselves distinctive, and those where the changes, although not entirely specific, suggested alcoholism as the cause.

Distinctive Changes. A deformity in the $\mathrm{T}$ wave that affected the electrocardiogram in 17 patients assumed one of three designs. 
The Dimple $T$ Wave. In this cardiogram, which was obtained in eight patients, the $\mathrm{T}$ appeared as a shallow and narrow dimple that interrupted the otherwise iso-electric S-U segment (Fig. 1 and 2). The deformity occurred in leads I and CR7 or CR4, and was by itself the only obvious fault in the tracing, except for a blunt T wave in CR4 in Case 1, a cloven T in CR4 in Case 2, and a deep and more orthodox inversion of the T in CR4 in Cases 7 and 8, although in these two instances also, the wave was narrow at its base.

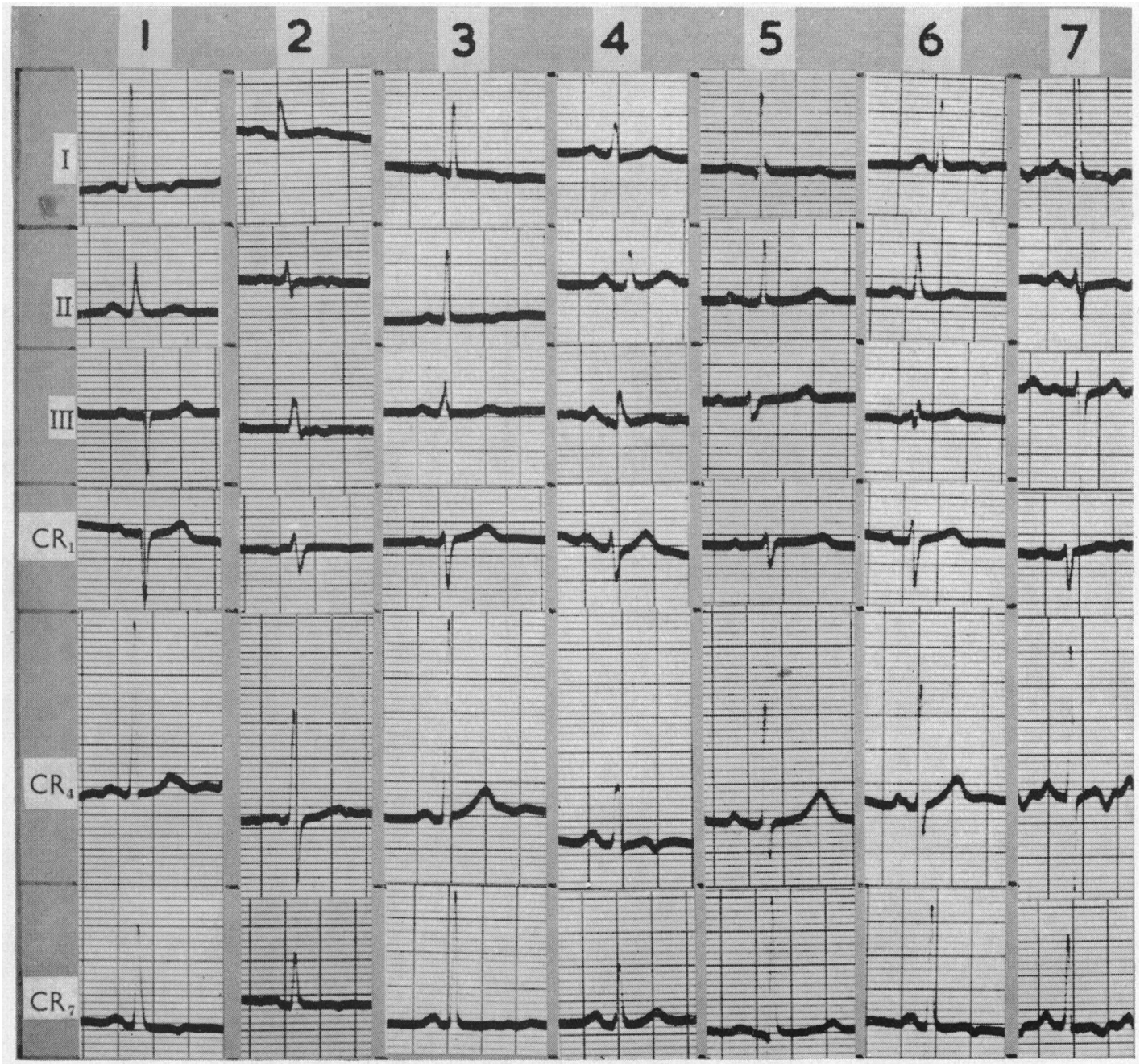

FIG. 1.-Dimple T waves in leads I and CR7 in Case 1, in leads II, III, CR4, and CR7 in Case 2, in leads I, II, and CR7 in Case 3, in lead CR4 in Case 4, in lead I in Case 5, and in leads I and CR7 in Cases 6 and 7.

This dimple T wave deformity, first described by Evans (1954) as a characteristic finding in the electrocardiogram of adult patients addicted to alcoholism, has also appeared sometimes in healthy youths under the age of 20 following a meal and disappearing after an overnight fast (Sears and Manning, 1958). This post-prandial electrocardiographic change, however, is not found as a lasting deformity in the tracing from an adult. Should a myocardial injury from coronary arterial 


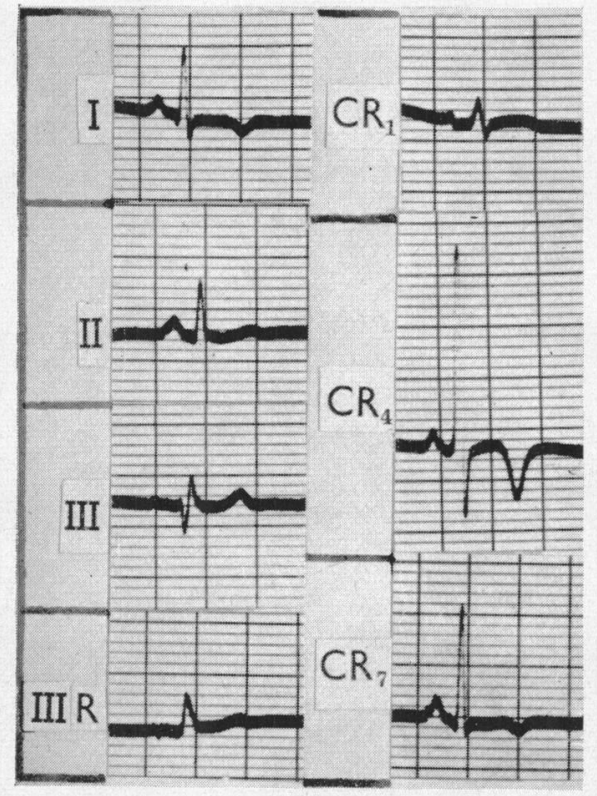

FIG. 2.-Dimple $\mathrm{T}$ wave in leads I and CR7 and deeper inversion of $T$ in CR4 which is characteristically narrow. disease be confined to a small area it is conceivable that a deformity resembling a dimple $T$ could result, but in patients suffering from cardiac pain, the cardiogram has not, in my experience, resembled the one described here for alcoholic cardiomyopathy, in that the chest leads show the more obvious changes characteristic of cardiac infarction.

The Cloven $T$ Wave. In seven patients the $T$ wave was low and showed a cleft at its summit. This deformity was usually seen in leads CR4 and CR7, while the $\mathrm{T}$ was low in lead $\mathrm{I}$ as well. In some other leads the $T$ was blunt. In four cases the rhythm was normal (Fig. 3), and in two auricular fibrillation was present (Fig. 4): the arrhythmia did not disturb this electrocardiographic sign in Case 13, but it is usually partly or wholly annulled by S-T depression following digitalis therapy as in Case 14 . In a seventh case the characteristic deformity was obscured during periods of transient bundle-branch block (Fig. 5).

In children a cloven $\mathrm{T}$ may be present in chest leads to the left of the sternum, but in this event it is a remnant of the inversion that characterises the $T$ wave over the right chest.

Although graphically the cloven $T$ would appear to be an earlier change than the dimple variety, the addition of auricular fibrillation or bundle-branch block, as happened in Cases 13, 14 and 15, suggests that the severity of the lesion, small as it doubtless is at the time these deformities occur, cannot be judged on this premise.

The Spinous T Wave. Benchimol and Schlesinger (1953) mentioned the presence of tall peaked $\mathrm{T}$ waves in patients with beriberi heart disease, but it is known that such $\mathrm{T}$ waves may appear occasionally in healthy subjects or during the early stages of cardiac infarction in some patients. The kind of deformity described here, which was met in two patients, differs from such peaked $T$ waves in that the $T$ is not necessarily tall, has a narrower base of from 0.10 to 0.15 second, and shows in spite of its subdued height, a pointed or spinous summit (Fig. 6). So far, this peculiar change in the $\mathrm{T}$ has not been seen in a myocardial injury from coronary arterial disease, while its presence in the two patients reported here, first suggested a diagnosis of alcoholic cardiomyopathy which was subsequently supported by certain clinical signs, and later by an admission of excessive alcohol consumption through many years.

The Blunt T Wave. Apart from the deformities of the $T$ wave already described, its blunting was noticed as an associated sign in three cases. The same change in leads over the right ventricle is not infrequently met with in some healthy children. Its presence in leads over the left ventricle on the other hand was regarded by Evans and McRae (1952) as indicative of a limited cardiac infarction in those with cardiac pain. The present study suggests that the appearance of a blunt $\mathrm{T}$ wave in left ventricular leads in a patient without chest pain points to alcoholic cardiomyopathy, although a diagnosis of painless and limited cardiac infarction cannot be altogether excluded. In the cases reported here, however, it was never a lone cardiographic sign, but was associated with either a dimple or cloven $\mathrm{T}$ in some other lead.

\section{Less Specific Changes}

Auricular Fibrillation. In two patients (Cases 13 and 14) the usual causes of this arrhythmia were absent. In this circumstance it has almost become custom to assume that coronary arterial 


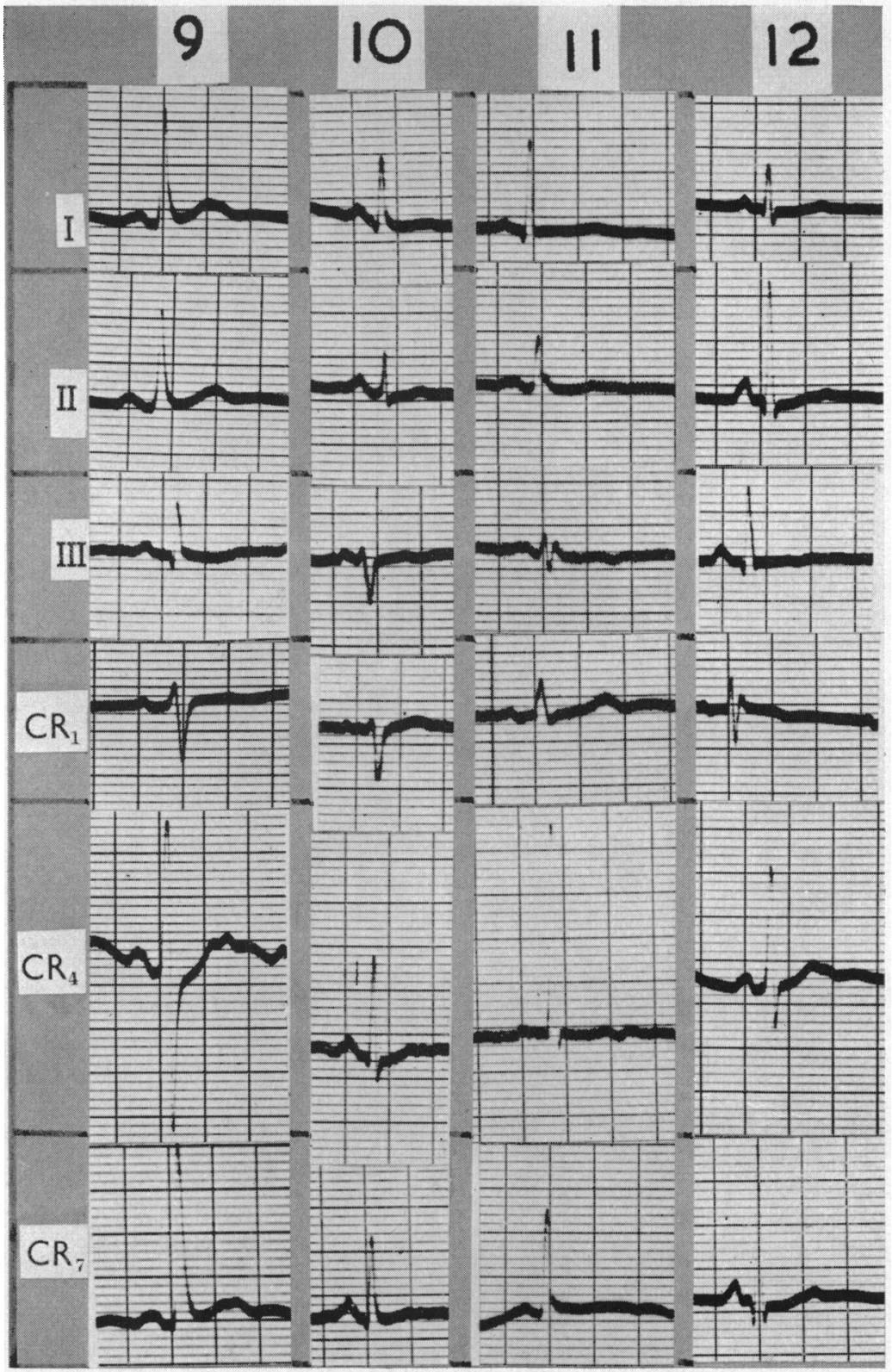

FIG. 3.-Cloven T wave in leads CR4 and CR7 in Cases 9 and 10, in lead CR4 in Case 11, and in lead II with blunting of T in CR4 in Case 12.

disease provides the cause, while the absence in the electrocardiogram of frank $T$ wave inversion has been explained by the interference by the fibrillation waves. The investigation has emphasized the need to seek first the history of alcoholism before naming coronary arterial disease as the cause of fibrillation in a patient in whom the usual causes of the arrhythmia are absent. Before commencing digitalis medication in such cases, the distinctive $T$ wave changes of alcoholic cardiomyopathy will help to substantiate the diagnosis, as happened in Case 13. 


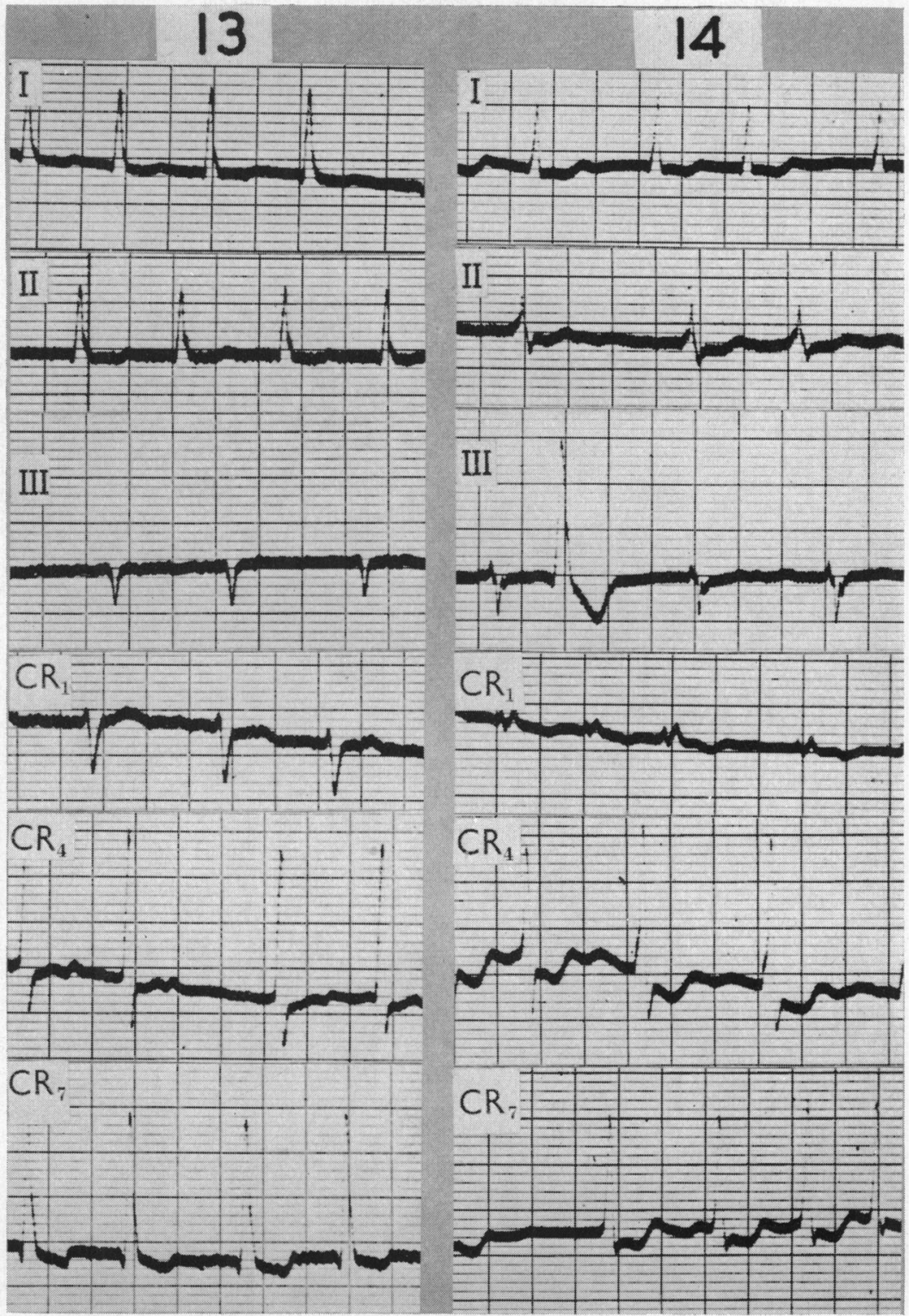

FIG. 4.-Cloven $T$ wave in lead CR4 in Case 13 with auricular fibrillation. S-T depression from digitalis medication has obscured any specific $T$ wave deformity, apart from lead III, in Case 14, which also shows auricular fibrillation and right bundle-branch block.

Extrasystoles. Extrasystoles, if frequent, if arising from several foci, and if occurring in association with moderate tachycardia, should always arouse suspicion that excessive alcohol consumption has been the cause. Extrasystoles occurred in 9 of the 20 patients and in seven of these they were found alongside a moderate tachycardia of 90 to 95 beats a minute. In six patients, characteristic $T$ wave changes appeared in addition to extrasystoles, which had not been regarded by themselves as unequivocally confirming the diagnosis of alcoholic cardiomyopathy, so that 


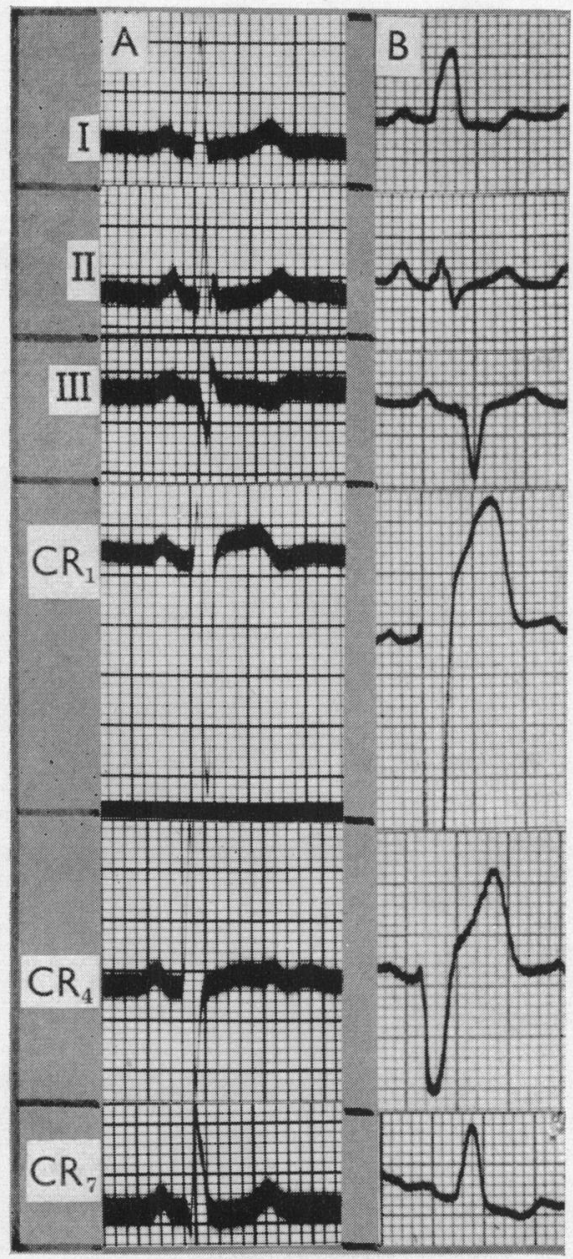

Fig. 5.-Cloven $T$ wave in lead CR4 when in normal rhythm (A), obscured by left bundle-branch block in (B). Case 15 .

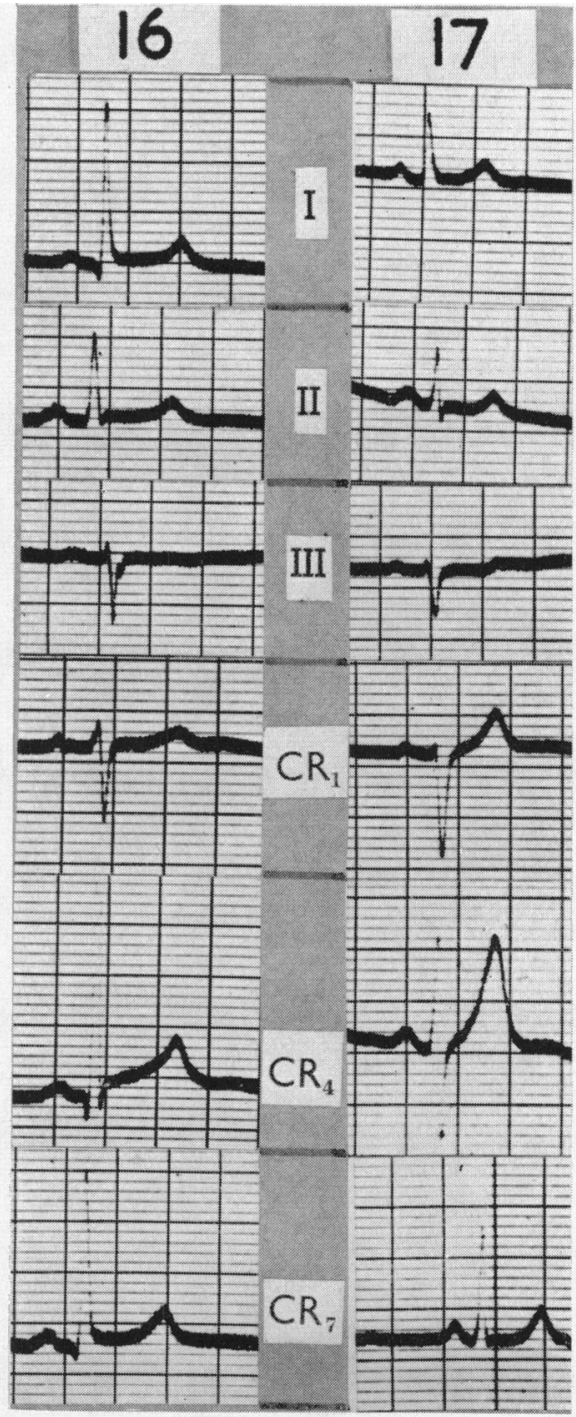

FIG. 6.-Spinous $T$ waves in leads $I$ and CR4 in Case 16, and in leads II and CR1 in Case 17.

characteristic extrasystoles as a single cardiographic sign served to help the recognition of the condition in three cases (Fig. 7 and 8).

Paroxysmal Tachycardia. Auricular tachycardia was present in two patients and in one (Case 19) it was of the repetitive kind. In both, alcoholic cardiomyopathy was suspected from the peculiar changes in the $\mathrm{T}$ wave, and in one a cloven $\mathrm{T}$ was found in an auricular extrasystole (Fig. 7).

Transient Bundle-Branch Block. This abnormal cardiogram, either in association with auricular fibrillation (Case 14) or with sinus rhythm (Case 15) may indicate a more active phase of the illness, for in the second patient a refusal to abstain from over-indulgence in alcohol led to his demise 


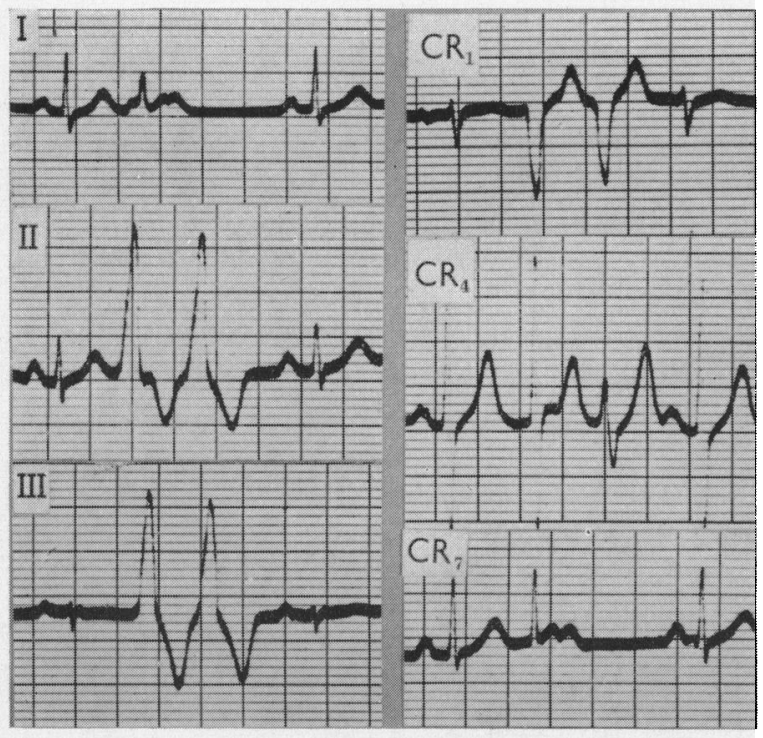

FIG. 7.-Multiple extrasystoles in Case 19. Cloven T wave in auricular extrasystole in lead I.

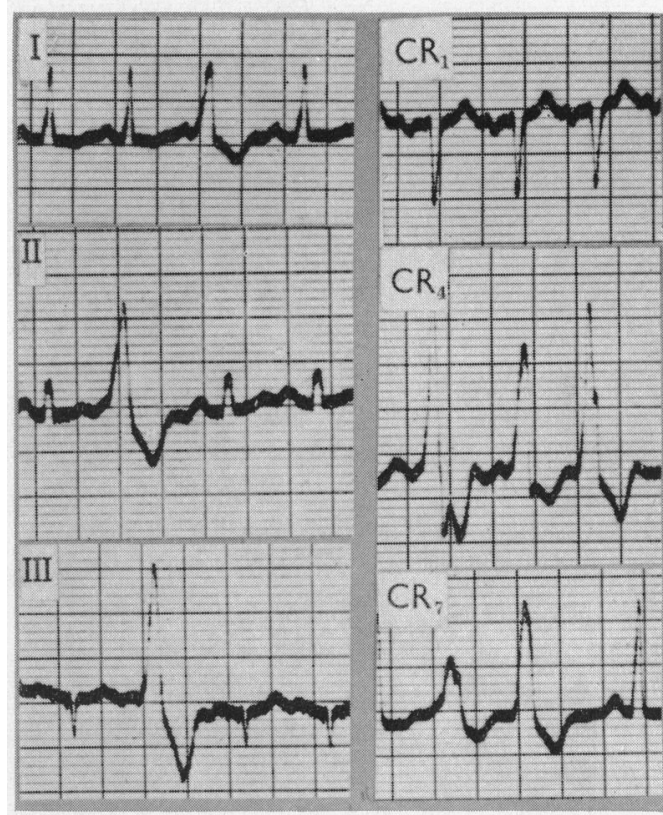

Fig. 8.-Multiple extrasystoles in Case 20 with S-T depression in leads I and CR7.

twelve months later from heart failure. In the first patient too there was much enlargement of the left ventricle and cerebral embolism had taken place following intracardiac thrombosis. Once bundle-branch block becomes established it is likely that heart failure is also present, in company with considerable cardiac enlargement: then both abstinence from alcohol and the addition of remedies intended to combat heart failure are unlikely to ameliorate the condition. Digitalis had deformed the $\mathrm{T}$ wave in one, but in the other a cloven $\mathrm{T}$ was the only abnormal feature of the cardiogram recorded during sinus rhythm (Fig. 5).

Depression of the $S-T$ Segment. When cardiac enlargement had assumed moderate proportions and heart failure had set in, with pulmonary congestion showing on radiological examination, as instanced by Cases 18 and 20, the S-T segment was depressed in leads I and CR7. In both patients alcoholic cardiomyopathy was suspected on the grounds of frequent extrasystoles in the presence of moderate tachycardia and not on the presence of non-specific S-T depression which would have obscured any distinctive $T$ wave changes had they been there, and especially when digitalis therapy had been added to combat the heart failure.

\section{The Electrocardiogram in Previously Reported Cases of Beriberi}

There is much confusion regarding the electrocardiogram in patients with beriberi and in the past it has been variously reported as being normal or abnormal.

Scott and Herrmann (1928) found no abnormality in the tracing from four patients with beriberi drawn from the rice-eating community of Louisiana. Wenckebach (1928) and Aalsmeer and Wenckebach (1929) stated that the electrocardiogram in beriberi was normal even in the worse instances of heart failure, and that it remained normal during the whole course of the illness. Keefer (1930), reporting 15 Chinese patients with heart failure from non-alcoholic beriberi, also stated that the electrocardiogram did not deviate from the normal, but one similar patient in Tokyo described by Hashimoto (1937) showed inversion of the $T$ wave. 
Weiss and Wilkins (1937), who wrote about dysfunction of the cardiovascular system from Vitamin $B_{1}$ deficiency in beriberi in patients who were heavy consumers of alcohol, found the electrocardiogram abnormal in 93 per cent of their 67 cases: in 62 of them there was a change in the direction of the $\mathrm{T}$ wave, and premature beats were present in 19. Jolliffe and Goodhart (1938) reported $T$ wave changes in four patients who were addicted to alcohol and had beriberi. Dustin et al. (1939), writing on the cardiogram in Vitamin $B_{1}$ deficiency, described changes in the $T$ wave in each of six cases, but stated that, as such changes occurred in many other conditions, it was necessary for their interpretation that the clinical findings should be known. Benchimol and Schlesinger (1953) published the findings in 22 alcoholic subjects with beriberi heart disease collected during three years: the electrocardiogram was normal in only two of them, the $T$ wave being inverted in three and abnormal in four others with left ventricular preponderance, and in one with left bundle-branch block: they stressed that all save one showed a normal heart rhythm. Eliaser and Giansiracusa (1956) found changes in the eleetrocardiogram in 57 per cent of their 94 patients who gave a history of alcoholism.

An important contribution to the subject of the electrocardiogram in beriberi heart disease has been made recently by Schrire (1958) from a study of 50 patients. The most significant feature was a normal tracing when the heart failure was at its worst, and $T$ wave inversion when failure symptoms were receding following treatment with thiamine. This change was so fleeting that it varied from day to day, and on occasion from ventricle to ventricle, so that it required daily electrocardiography for its detection. In eight of his patients the tracing remained normal throughout the illness.

\section{The Cause of the Faulty Electrocardiogram}

The pathological changes in the heart from excessive alcoholism are not always uniform. As far back as 1873 Walshe described what he regarded as a rare affection of the heart that he had observed in subjects of chronic alcoholism. It consisted of a localized cirrhosis occurring in limited areas of islets in the ventricular walls or columnæ carneæ; he opined that it was not chronic myocarditis. The infiltrated material was sometimes structureless, sometimes obscurely fibroid, and it might undergo fatty metamorphosis. He added that such cirrhotic state of the heart's texture occurred independently of any perverted state of its circulation. Subsequent writers, particularly Weiss and Wilkins (1937), have described the changes in the myocardium as a hydropic degeneration of muscle and conducting fibres, with an increase in the intercellular substances, and without alteration of its water content. They stated that the weight of the heart might be normal, although subsequent writers, e.g. Benchimol and Schlesinger (1953), have reported hypertrophy and dilatation of both left and right ventricles. In the two patients belonging to this series who died, necropsy was not obtained. The narrowness of the deformed $T$ wave in the electrocardiogram, always in the absence of significant $Q$ waves and depression of the $S-T$ segment, suggests that in this early phase of alcoholic cardiomyopathy, the myocardial injury, whatever its exact nature, is confined to limited units of muscle fibres, and is capable of complete resolution and recovery once the damaging agent, namely spirit-drinking, is removed, without leaving behind it any residual fibrotic changes. Naturally, a continuation of alcoholic addiction can produce lasting changes in the electrocardiogram in the form of S-T depression and established bundle-branch block associated with fibrotic areas in a hypertrophied myocardium.

The pathogenesis of alcoholic affection of the heart is customarily linked up with thiamine deficiency, giving rise to the beriberi syndrome, as happens in the oriental when polished rice forms the staple article of diet. Alcohol, a food substance supplying the body with a surfeit of calories but with a minimum quantity of Vitamin $\mathbf{B}_{1}$, provides the soil for the development of a like syndrome in the occident.

In the case of alcoholic "myocardosis", however, Eliaser and Giansiracusa (1956) believe that the condition is not entirely related to vitamin deficiency, but that it is the outcome of a toxic action 
on the heart muscle. These authors actually incriminate the cumulative effects of ethanol on the heart muscle, and as the toxic effect of alcohol increases in the presence of impaired liver function, they considered this to be an important factor in the production of changes in several other organs including the heart.

\section{The Incidence of Alcoholic Heart Disease}

Through many years there has been mention of the effects of alcohol on the heart. In 1892 Sansom wrote that alcoholic intemperance may combine with over-indulgence in the pleasures of the table to produce baneful effects upon the heart and vessels. Steell (1906) spoke of the capricious distribution of dropsy in cases of cardiac muscle-failure of beer drinkers and of the disease known as beriberi. Mackenzie (1908) held that there could be little doubt that dilatation of the heart and weakness of its muscle leading to heart failure resulted from arsenic which contaminated beer or from arsenic combined with beer, for such cases were not seen when such contamination ceased. In more recent years the readier recognition of cardiac effects of alcoholism has been frustrated by the belief that its clinical manifestations are akin to oriental beriberi. Admittedly, they can be, but they are not exclusively so, and Weiss and Wilkins (1937) emphasized that the occidental kind of beriberi differed from the oriental kind in that it presented with signs of left ventricular affection. Brigden (1957) brought into prominence a group of patients in whom heart failure results from non-coronary disease of the myocardium, and included among his cases were 13 with alcoholic cardiomyopathy, a condition that he emphasized was still not widely accepted.

There appear to be three reasons why its recognition in the past has gone unheeded. First, there has been a demand for the presence of criteria that indicate a so-called high output or hyperkinetic heart failure before a diagnosis of alcoholic affection of the heart is warranted. Secondly, a history of excessive alcohol has not been obtained. The patient rarely volunteers the information, nor does he admit such over-indulgence in response to casual inquiry. The information is usually gained after rigorous questioning, and sometimes the truth is only obtained at an interview with the spouse or the family doctor. Thirdly, the finding of an enlarged left ventricle, coupled with some abnormality in the electrocardiogram, and in the absence of hypertension or valvular heart disease, has been regarded too often as indicating coronary arterial disease even in the absence of cardiac pain.

\section{The Clinical Features}

The assembling of the 20 cases reported here during a relatively short period in private practice, has emphasized that injurious effects on the heart from habitual spirit drinking are not uncommon in this country. The investigation has also emphasized the stealthy onset of such injurious effects, for at the start the symptoms are light and bizarre and only become obvious when the myocardium has been more severely affected. Moreover, it has been shown that abstinence from alcohol early in the illness can halt the myocardial damage (Fig. 9); but should the condition go undiscovered, and this is a common happening, or should it go unheeded by the patient, the illness reaches a stage where treatment is of no avail, for the changes in the heart muscle have then become irreparable.

All 20 patients were men. Their ages varied from 39 to 74 and the average was 55 years. They followed diverse occupations, but the majority held executive positions. Few pursued any energetic recreation, but many played at golf; none excelled at the game, but all shared actively in the amenities offered at the club house.

Breathlessness was the commonest symptom and was present in ten, being severe in four. Chest pain, which occurred in six, did not once resemble cardiac pain in regard to its site, character, or response to either exercise or rest. Often, however, it was a presenting symptom and it gained in importance when a subsequent cardiogram showed changes in the $T$ wave that too often led to an acceptance of a cardiac source for the pain. Palpitation was a prominent symptom in five 


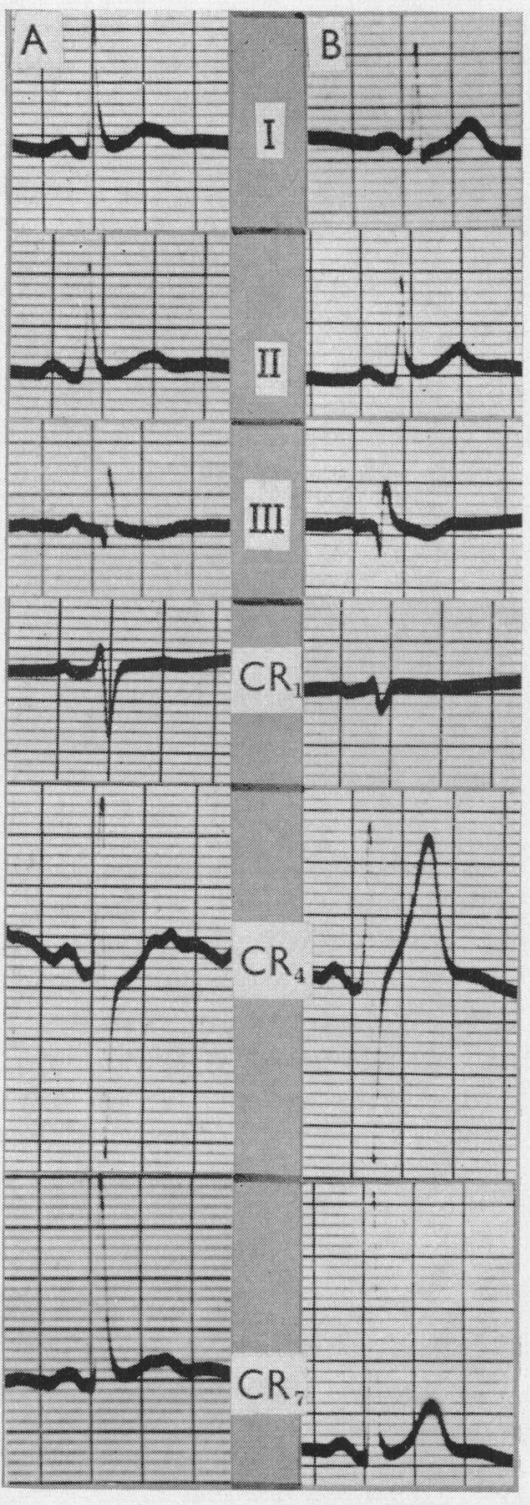

FIG. 9.-Cloven $\mathrm{T}$ in leads CR4 and CR7, and blunt $T$ in $I(A)$, changes that are absent from (B) recorded after a period of abstinence from alcohol. and two of these had paroxysmal tachycardia. Two were liable to gout, and three mentioned profuse sweating. In none was there neuritic pain. Four gave a history of pneumonitis in the past. The symptomatology, therefore, was seldom impressive, and the patient had been referred by the family doctor for examination, either to explain the patient's unfitness in the absence of obvious physical signs, or to account for certain abnormal signs observed on clinical examination. Either at this stage or later, and especially subsequent to electrocardiography, a history of alcoholism was sought. All 20 patients were "heavy drinkers." Although information as to precise quantities was difficult to obtain, even following close questioning, the usual consumption was more than "half a bottle" of spirits a day, either in the form of gin or whisky, for periods varying from 4 to 20 years. Fourteen drank spirits only, and six took beer as well, one only partaking of more beer than spirits. The extent to which, they smoked caused surprise. Thus, only one smoked excessively, eight smoked moderately, six smoked lightly and five not at all.

On clinical examination they were mostly, though not invariably, of a robust build. They were all well-nourished, 14 were overweight, and four especially so. The pulse was often rapid and the association of this with extrasystoles has been more fully described in connection with the electrocardiogram. In six the pulse-pressure was increased from a slight or moderate rise of the systolic blood pressure, and on this account a diagnosis of hypertension had been suggested in three. An increase in the venous pulse was noticeable in three. Triple heart rhythm was heard in four, from addition of the third heart sound in two and the auricular sound in two. None had heart murmurs. The liver was considered to be enlarged in five, but none had ascites. Edema occurred in the two patients who died and in one other.

The electrocardiogram is separately described. At cardioscopy the left ventricle was found to be moderately enlarged in nine and considerably enlarged in one. Pulmonary congestion was present in five (see Table I).

\section{Classification of Alcoholic Heart Disease}

From the foregoing analysis of symptoms in 20 patients, from a study of the literature, and having in mind the need to facilitate the earlier diagnosis of the condition, it seems expedient to assign patients with alcoholic heart disease into two main groups, namely those with alcoholic cardiomyopathy, and those with complicated cardiomyopathy.

Thus, in alcoholic cardiomyopathy the patients are usually well-nourished and frequently obese. Their symptoms are of a light character at the start and they include breathlessness on exertion, pain in the chest that does not resemble cardiac pain, and palpitation. 
TABLE I

PREMIER FINDINGS IN 20 PATIENTS WITH ALCOHOLIC CARDIOMYOPATHY

\begin{tabular}{|c|c|c|c|c|c|c|c|c|c|c|c|c|}
\hline \multirow[b]{2}{*}{$\begin{array}{c}\text { Case } \\
\text { number }\end{array}$} & \multirow[b]{2}{*}{ Age } & \multirow[b]{2}{*}{ Nutrition } & \multirow[b]{2}{*}{ Symptoms } & \multirow[b]{2}{*}{$\begin{array}{c}\text { Heart } \\
\text { rate }\end{array}$} & \multirow[b]{2}{*}{$\begin{array}{l}\text { Heart } \\
\text { rhythm }\end{array}$} & \multirow[b]{2}{*}{$\begin{array}{c}\text { Raised } \\
\text { venous } \\
\text { pres- } \\
\text { sure }\end{array}$} & \multirow[b]{2}{*}{$\begin{array}{l}\text { Triple } \\
\text { rhythm }\end{array}$} & \multirow[b]{2}{*}{$\begin{array}{c}\text { Liver } \\
\text { en- } \\
\text { large- } \\
\text { ment }\end{array}$} & \multirow[b]{2}{*}{ CEdema } & \multicolumn{2}{|c|}{ Cardioscopy } & \multirow[b]{2}{*}{$\begin{array}{l}\text { Electro- } \\
\text { cardiogram }\end{array}$} \\
\hline & & & & & & & & & & $\begin{array}{l}\text { Left } \\
\text { ven- } \\
\text { tricle } \\
\text { en- } \\
\text { larged }\end{array}$ & $\underset{\begin{array}{c}\text { Hilar } \\
\text { conges- } \\
\text { tion }\end{array}}{\mid}$ & \\
\hline 1 & 49 & Stout & Breathlessness & 100 & Natural & 0 & 0 & 0 & 0 & 0 & 0 & Dimple $\mathbf{T}$ wave \\
\hline 2 & 64 & Stout & $\begin{array}{l}\text { Breathlessness } \\
\text { Chest pain }\end{array}$ & 85 & Extrasystoles & 0 & 0 & 0 & 0 & 0 & 0 & $\begin{array}{l}\text { Extrasystoles } \\
\text { Dimple T waye }\end{array}$ \\
\hline 3 & 56 & Natural \{ & $\begin{array}{l}\text { Tiredness } \\
\text { Breathlessness }\end{array}$ & 75 & Natural & + & 0 & 0 & 0 & 0 & 0 & Dimple $T$ wave \\
\hline 4 & 60 & Natural & $\begin{array}{l}\text { Tiredness } \\
\text { Chest pain }\end{array}$ & 100 & Natural & 0 & 0 & 0 & 0 & 0 & 0 & Dimple $\mathbf{T}$ wave \\
\hline 5 & 60 & Stout & $\begin{array}{l}\text { Palpitation } \\
\text { Sleeplessness }\end{array}$ & 74 & Extrasystoles & 0 & 0 & + & 0 & + & + & Extrasystoles \\
\hline 6 & 51 & $\begin{array}{l}\text { Very } \\
\text { stout }\end{array}$ & Chest pain & 85 & Natural & 0 & 0 & 0 & 0 & 0 & 0 & $\begin{array}{l}\text { Dimple I wave } \\
\text { Dimple T wave }\end{array}$ \\
\hline 7 & 54 & Stout & Palpitation & 95 & Extrasystoles & 0 & + & + & 0 & + & 0 & Extrasystoles \\
\hline 8 & 48 & $\begin{array}{l}\text { Very } \\
\text { stout }\end{array}$ & Breathlessness & 76 & Natural & 0 & 0 & 0 & & + & 0 & Dimple T wave \\
\hline 9 & 53 & Stout & Giddiness & 72 & Natural & 0 & 0 & 0 & 0 & 0 & 0 & Cloven $T$ wave \\
\hline 10 & 43 & Stout & $\begin{array}{l}\text { Sweating } \\
\text { Palpitation }\end{array}$ & 95\{ & $\begin{array}{l}\text { Extrasystoles } \\
\text { Paroxysmal } \\
\text { tachycardia }\end{array}$ & 0 & 0 & 0 & 0 & 0 & 0\{ & $\begin{array}{l}\text { Extrasystoles } \\
\text { Cloven T wave }\end{array}$ \\
\hline $\begin{array}{l}11 \\
12\end{array}$ & $\begin{array}{l}61 \\
53\end{array}$ & $\begin{array}{l}\text { Natural } \\
\text { Natural }\end{array}$ & $\begin{array}{l}\text { Chest pain } \\
\text { Breathlessness }\end{array}$ & $70^{\prime}$ & $\begin{array}{l}\text { Natural } \\
\text { Natural }\end{array}$ & $\begin{array}{l}\mathbf{0} \\
0\end{array}$ & $\begin{array}{l}0 \\
0\end{array}$ & $\begin{array}{l}0 \\
0\end{array}$ & $\begin{array}{l}0 \\
0\end{array}$ & $\begin{array}{l}0 \\
0\end{array}$ & $\begin{array}{l}0 \\
0\end{array}$ & $\begin{array}{l}\text { Cloven } \mathbf{T} \text { wave } \\
\text { Cloven } \mathbf{T} \text { wave }\end{array}$ \\
\hline 13 & 45 & Stout & $\begin{array}{l}\text { Breathlessness } \\
\text { Tiredness }\end{array}$ & 100 & $\begin{array}{l}\text { Auricular } \\
\text { fibrillation }\end{array}$ & 0 & 0 & 0 & + & + & + & $\begin{array}{l}\text { Auricular } \\
\text { fibrillation } \\
\text { Cloven }\end{array}$ \\
\hline 14 & 60 & Stout & $\begin{array}{l}\text { Breathlessness } \\
\text { Sweating }\end{array}$ & 110 & $\begin{array}{l}\text { Auricular } \\
\text { fibrillation }\end{array}$ & 0 & 0 & 0 & 0 & + & 0 & $\begin{array}{l}\text { Auricular } \\
\text { fibrillation } \\
\text { Cloven } T \text { wave }\end{array}$ \\
\hline 15 & 39 & Natural & Breathlessness & 100 & Natural & + & + & + & + & 0 & + & Transient bundle- \\
\hline 16 & 58 & Natural & Gout & 73 & Natural & 0 & 0 & 0 & 0 & + & 0 & $\begin{array}{l}\text { Cloven } T \text { wave } \\
\text { Spinous } T \text { wave }\end{array}$ \\
\hline 17 & 74 & Stout & $\begin{array}{l}\text { Breathlessness } \\
\text { Palpitation }\end{array}$ & 70 & Extrasystoles & 0 & 0 & 0 & 0 & + & 0 & Spinous $T$ wave \\
\hline 18 & 61 & $\begin{array}{l}\text { Very } \\
\text { stout }\end{array}$ & $\begin{array}{l}\text { Chest pain } \\
\text { Gout }\end{array}$ & 120 & Extrasystoles & 0 & + & 0 & 0 & + & +\{ & Extrasystoles \\
\hline 19 & 58 & $\begin{array}{l}\text { Very } \\
\text { stout }\end{array}$ & $\begin{array}{l}\text { Palpitation } \\
\text { Giddiness }\end{array}$ & 74\{ & $\begin{array}{l}\text { Extrasystoles } \\
\text { Paroxysmal } \\
\text { tachycardia }\end{array}$ & 0 & 0 & + & 0 & 0 & 0 & $\begin{array}{l}\text { Multiple } \\
\text { extrasystoles }\end{array}$ \\
\hline 20 & 53 & Stout & $\begin{array}{l}\text { Breathlessness } \\
\text { Chest pain }\end{array}$ & 110 & Extrasystoles & + & + & + & + & + & +\{ & $\begin{array}{l}\text { Extrasystoles } \\
\text { S-T depression }\end{array}$ \\
\hline
\end{tabular}

Cases 14 and 19 died.

Clinical examination may discover an arrhythmia, commonly due to extrasystoles which are often multiple, arising from several foci, and occurring in the presence of a moderate tachycardia, or sometimes due to auricular fibrillation. Triple heart rhythm may be heard in the later stage. A slight or greater degree of left ventricular enlargement may be found at cardioscopy, and later in the illness pulmonary congestion is added.

Distinctive signs are present in the electrocardiogram and it is these that clinch the diagnosis, and prompt a relentless questioning concerning the daily consumption of spirits through many years, unless the patient readily admits this habit.

Should the condition be recognized early on, abstinence from spirit-drinking will ensure a successful emergence from the illness, but should addiction to alcohol continue, as was the case in 2 of the 20 patients reported here, the illness progresses into its intractable form.

In complicated alcoholic cardiomyopathy vascular effects are added to the cardiac. There may be great breathlessness with œdema of the ankles, even amounting to generalized anasarca with ascites. The peripheral pulses are bounding in character with a raised pulse pressure and a warm skin as in high output cardiac failure. The heart rate is rapid and usually normal rhythm is maintained. The circulation time is increased. The venous pressure is raised and triple heart rhythm is common. On radiological examination there is usually considerable generalized enlargement of the heart to be seen which may be accompanied by hilar congestion. The electrocardiogram often shows right bundle-branch block. In the absence of this conduction defect the tracing at times, even when the 
heart is greatly enlarged, may be normal, and inversion of the $\mathrm{T}$ wave is a fugitive change in this beriberi type of heart failure.

Added to these several signs may be others due to the injurious effects of alcohol on other systems, such as cirrhosis of the liver, gout, or peripheral neuritis.

\section{CONCLUSIONS}

In 20 consecutive patients with alcoholic cardiomyopathy, abnormalities in the electrocardiogram were considered to be distinctive in 17 , and although not so specific in the remaining 3 , they suggested the diagnosis in these patients also.

The distinctive electrocardiographic deformities were limited to the $T$ wave which was a depressed dimple in eight patients, upright and cloven in seven, and spinous in two. Whenever the $T$ wave in chest leads was obviously inverted, as happened in two patients, the narrowness of the wave remained as a characteristic feature, and differed from the changes usually met in cardiac infarction.

In three patients the presence of extrasystoles suggested the diagnosis in that they were multiple, arose from different foci, or were associated with moderate tachycardia. Extrasystoles were also present in company with the distinctive signs in six other patients. Auricular fibrillation was found in two patients, and paroxysmal auricular tachycardia in another two.

Bundle-branch block, present in two patients, and depression of the S-T segment in two, were regarded as sinister signs, for they occurred in the presence of enlargement of the heart with failure. Two patients exhibiting such cardiographic signs died. With these exceptions, abstinence from alcohol, together with digitalization in the two patients with fibrillation, sufficed to return the patient to health, and without the addition of thiamine therapy.

This investigation has brought proof that addiction to habitual and excessive spirit-drinking is prevalent, and that its injurious effects on the heart often go unrecognized. Moreover, it has shown that the early diagnosis of alcoholic cardiomyopathy is most rewarding, for abstinence from spiritdrinking before it has progressed to the more serious phase of complicated alcoholic myocardosis, will enable the patient to regain his customary health. Familiarity with the electrocardiographic abnormalities identified with alcoholic cardiomyopathy will help to attain this desirable objective.

\section{REFERENCES}

Aalsmeer, W. C., and Wenckebach, K. F. (1929). Herz und Kreislauf bei der Beriberi Krankheit. Berlin. Benchimol, A. B., and Schlesinger, P. (1953). Amer. Heart J., 46, 245.

Brigden, W. (1957). Lancet, 2, 1179 and 1243.

Dustin, C. C., Weyler, H., and Roberts, C. P. (1939). New Eng. J. Med., 220, 15.

Eliaser, M., and Giansiracusa, F. J. (1956). California Med., 84, 234.

Evans, W. (1954). Cardiography. 2nd ed. Butterworths. London.

, and McRae, C. (1952). Brit. Heart J., 14, 429.

Hashimoto, H. (1937). Amer. Heart J., 13, 580.

Jolliffe, N., and Goodhart, R. (1938). J. Amer. med. Ass., 111, 380.

Keefer, C. S. (1930). Arch. intern. Med., 45, 1.

Mackenzie, J. (1908). Diseases of the Heart. London.

Sansom, A. E. (1892). Diseases of the Heart and Thoracic Aorta. London.

Schrire, V. (1958). Internat. Cardiol. Congress. Brussels.

Scott, R. C., and Herrmann, G. R. (1928). J. Amer. med. Ass., 90; 2083.

Sears, G. A., and Manning, G. W. (1958). Amer. Heart J., 56, 591.

Steell, G. (1906). Textbook on Diseases of the Heart. Manchester.

Walshe, W. H. (1873). Diseases of the Heart and Great Vessels. 4th ed. London.

Weiss, S., and Wilkins, R. W. (1937). Ann. intern. Med., 11, 104.

Wenckebach, K. F. (1928). Lancet, 2, 265. 